\title{
Erratum to: Companion planting attract-and-kill method for wireworm management in potatoes
}

\author{
Robert S. Vernon ${ }^{1} \cdot$ Willem G. van Herk ${ }^{1} \cdot$ Markus Clodius $^{1} \cdot$ Jeff Tolman $^{2}$
}

Published online: 24 December 2015

(C) Springer-Verlag Berlin Heidelberg 2015

\section{Erratum to: J Pest Sci \\ DOI 10.1007/s10340-015-0707-6}

Unfortunately, there is an error in the Table $3 b$ in the original publication which has been corrected using the correct version.

It is also been corrected by erratum.

The online version of the original article can be found under doi:10.1007/s10340-015-0707-6.

Robert S. Vernon

bob.vernon@agr.gc.ca

Willem G. van Herk

wim.vanherk@agr.gc.ca

1 Agassiz Research and Development Centre, Agriculture and Agri-Food Canada, P.O. Box 1000, Agassiz, BC V0M 1A0, Canada

2 Southern Crop Protection and Food Research Centre, Agriculture and Agri-Food Canada, 1391 Sandford Street, London, ON N5V 4T3, Canada 


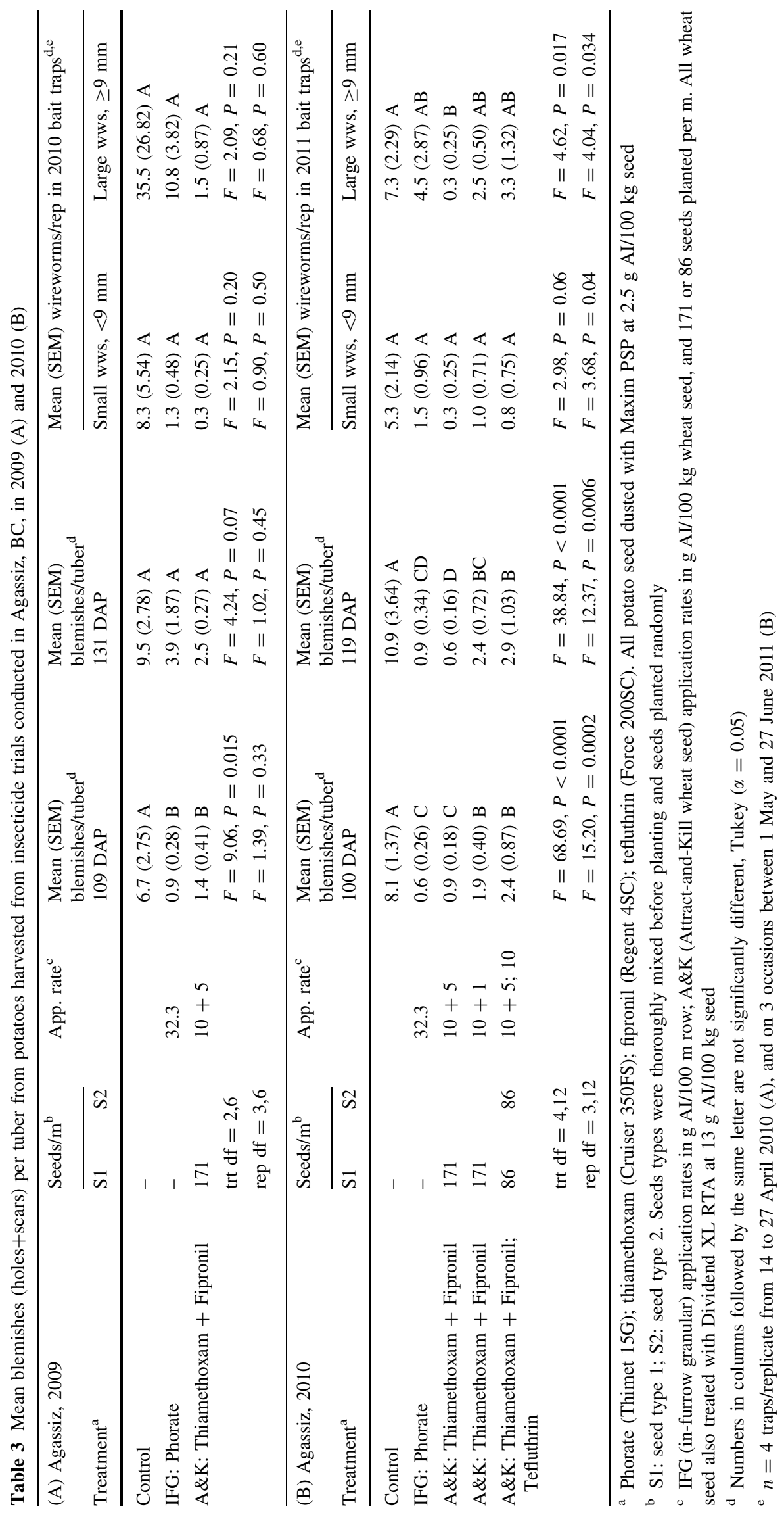

